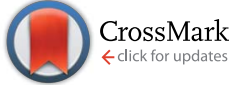

Cite this: J. Mater. Chem. A, 2016, 4, 17154

Received 23rd September 2016 Accepted 14th October 2016

DOI: $10.1039 / c 6 t a 08288 b$

www.rsc.org/MaterialsA

\title{
Halide-regulated growth of electrocatalytic metal nanoparticles directly onto a carbon paper electrode $\uparrow$
}

\begin{abstract}
Yaovi Holade, David P. Hickey and Shelley D. Minteer*
Direct growth of hierarchical micro/nanostructured metal arrays on a 3D substrate is a powerful tool to enhance the catalytic efficiency of metal particles towards a wide range of substrates. In this contribution, we demonstrate a novel and versatile method for growing anisotropic microstructures directly onto a 3D carbon paper electrode, using $\mathrm{Au}, \mathrm{Pd}$ and $\mathrm{Pt}$ nanoparticles as elementary building blocks. It was determined that halides play a crucial role in the morphology of synthesized Au particles, leading to either complex flower-like rough surfaces (exhibiting high catalytic activity) or featureless smooth surfaces (exhibiting low catalytic activity). Of the three metal materials studied, the Pt decorated carbon paper (Pt@carbon) material exhibits a high electrocatalytic activity toward the oxygen reduction reaction in an alkaline medium. We demonstrate that this new Pt material can operate as a cathode in an alkaline glucose fuel cell exhibiting outstanding peak power density of $2-3 \mathrm{~mW} \mathrm{~cm}^{-2}$ (using an anode of Au@carbon or Pt@carbon at room temperature and low metal loading without any fuel circulation). This newly described fabrication approach allows for the rational control of metallic particle growth, paving a new way towards materials with regulated surface roughness allowing for tuneable physical, optical and catalytic properties.
\end{abstract}

\section{Introduction}

The development of electrochemical energy conversion devices, such as solid alkaline membrane fuel cells (SAMFCs) that utilize alcohols as a fuel source, is of paramount importance. Their effectiveness requires the design of innovative procedures for synthesizing advanced electrode materials that help to optimize the catalytic efficiency while reducing the metal catalyst loading. Therefore, seeking highly active and durable catalysts has become a prerequisite for achieving efficiency in both the oxygen reduction reaction (ORR) and alcohol oxidation. An ideal catalytic material should have a high dispersion of the active sites, controllable surface structure and morphology, and minimal metal loading that allow for optimization of activity, selectivity, and durability. For platinum group metals (PGMs), the most widely used approaches rely on engineering materials with tuneable surface structure and composition, such as coreshell materials and multimetallic nanoalloys. ${ }^{1-7}$ Another common approach for increasing the efficiency of metallic nanoparticles (NPs) is to partially or completely remove

Departments of Chemistry and Materials Science and Engineering, University of Utah, 315 S 1400 E Rm 2020, Salt Lake City, Utah, 84112, USA. E-mail: minteer@chem.utah. $e d u$

$\dagger$ Electronic supplementary information (ESI) available: UV-Vis spectra, additional tables, additional scheme, additional SEM images, additional CVs. See DOI: 10.1039/c6ta08288b a sacrificial component in alloys, so that the removal of the more reactive metal leads to nanocages ${ }^{8-10}$ or nanoframes ${ }^{11-13}$ with well-defined and controllable facets. The obtained materials exhibit nanoscale defects in their channels and on their pore walls, which are of particular interest for most catalytic applications because these sites are often a source of catalytic activity. The majority of existing synthetic methodologies require materials to be stabilized in a liquid or dispersed in a powder before using a binder, such as Nafion, to immobilize the NPs on a substrate (i.e. glassy carbon) prior to use. While the use of a Nafion ionomer contributes to the proton transport within the electrode materials, the use of such binders adds a layer of complexity to the fabrication process, and degradation of binders results in the undesired loss of NPs and subsequent decrease in catalytic performance. ${ }^{14-16}$ Thus far, only a few attempts have been devoted to direct synthesis of NPs onto an electrode surface such as carbon paper to further reduce these issues. One of the solutions was the self-assembled 3D metallic nano-architectures, which have received tremendous interest in catalysis. ${ }^{17-20}$ Hence, direct syntheses of NPs onto carbon papers or glassy carbon have been initiated from methods of electrodeposition, ${ }^{19-23}$ electrospinning, ${ }^{24-26}$ and wall-jet configuration. ${ }^{27}$ However, these methods result in high loading of precious metals and loss of catalytic activity due to the packing of NPs inside the electrode fibers. Furthermore, many attempts have been made to use the halide anion, $\mathrm{Br}^{-}$, as a capping agent to regulate the aqueous synthesis of Pd and Ag NPs in a polyol- 
based system. ${ }^{28,29}$ The effect of halide ions on the growth rate of NPs in solution has been addressed during the last ten years and the obtained particles have a smooth surface, mostly from pre-made small seeds. ${ }^{30}$ However, it is still unknown how other halides, such as $\mathrm{Cl}^{-}, \mathrm{Br}^{-}$and $\mathrm{I}^{-}$, could impact the direct growth of metallic particles on a $3 \mathrm{D}$ substrate and subsequently the electrochemical performances.

To address all these challenges, we report herein a versatile chemical method to grow 3D metallic microstructures at the surface of carbon paper. The success of this approach for in situ growth relies on a control of the reaction time together with the use of halide anions, $\mathrm{Br}^{-}$and $\mathrm{I}^{-}$, as effective tools. We discovered that the incorporation of $\mathrm{Br}^{-}$into the reaction mixture is critical for tailoring both highly rough surfaces and intrinsic catalytic activity of Au decorated carbon paper (Au@carbon paper), thus contributing to high electrocatalytic activity of the resulting particles towards glucose oxidation and excellent stability. Since the particles are directly deposited onto the carbon paper, there is no need to prepare a catalytic ink, which enables (i) bypassing the use of binders, (ii) avoiding active siteobstruction, (iii) minimizing metal detachment from the electrode, and (iv) preventing particle agglomeration.

\section{Experimental}

\section{Chemicals and materials}

Untreated Toray carbon paper TGP-H-060 was purchased from Fuel Cell Earth (see Fig. S1 $\dagger$ ). Trihydrate tetrachloroauric(III) acid $\left(\mathrm{HAuCl}_{4} \cdot 3 \mathrm{H}_{2} \mathrm{O}, 99.9 \%\right)$, potassium tetrachloropalladate(II) $\left(\mathrm{K}_{2} \mathrm{PdCl}_{4}, 99.99 \%\right)$, hexahydrate hexachloroplatinic(Iv) acid $\left(\mathrm{H}_{2} \mathrm{PtCl}_{6} \cdot 6 \mathrm{H}_{2} \mathrm{O}, 37.50 \% \mathrm{Pt}\right.$ basis $)$, lead(II) nitrate $\left(\mathrm{Pb}\left(\mathrm{NO}_{3}\right)_{2}\right.$, $\geq 99.0 \%)$ and $\mathrm{D}-(+)$-glucose $(99.5 \%)$ were obtained from SigmaAldrich. Potassium bromide (KBr, 99.6\%) and potassium chloride (KCl, 100\%) were purchased from Fisher Scientific. Potassium iodide (KI) was purchased from Amresco® (USA). Potassium nitrate $\left(\mathrm{KNO}_{3}\right)$ and sodium hydroxide $(\mathrm{NaOH}, 97 \%)$ were purchased from MACRON Fine Chemicals ${ }^{\mathrm{TM}}$. Potassium sulphate $\left(\mathrm{K}_{2} \mathrm{SO}_{4}, 100 \%\right)$ was supplied from J. T. Baker (USA). $\mathrm{L}-(+)$ ascorbic acid (AA, >99\%) was purchased from Research Products International Corp. (USA). All chemicals were used as received. All name ultra-pure water is provided from Milli-Q Millipore source (MQ: $18.2 \mathrm{M} \Omega \mathrm{cm}$ at $20^{\circ} \mathrm{C}$ ).

\section{Synthesis of anisotropic particles on Toray carbon paper}

The synthesis was performed using a square of $5 \mathrm{~cm}$ sides as exposed areas, $\left(2 \times 25 \mathrm{~cm}^{2}\right.$ available for both sides $)$ of TGP060-H Toray carbon paper (bulk density: $0.4514 \pm 0.003 \mathrm{~g} \mathrm{~cm}^{-3}$ ).

$\mathrm{Au}$ @carbon paper in the presence of $\mathrm{Br}^{-}$: effect of the reaction time. $20.0 \mathrm{mg}$ of $\mathrm{HAuCl}_{4} \cdot 3 \mathrm{H}_{2} \mathrm{O}$ that corresponds to $\mathrm{ca}$. $4 \mathrm{wt} \% \mathrm{Au}$ (i.e. $0.2 \mathrm{mg}_{\text {metal }} \mathrm{cm}^{-2}$ ) were dissolved with $20 \mathrm{~mL} \mathrm{MQ}$ water $(2.5 \mathrm{mM})$ and gently shacked for $10 \mathrm{~min}$ using a MultiPurpose-Rotator (Thermo Scientific, Model no. 2314). Then, $72.5 \mathrm{mg} \mathrm{KBr}(30.5 \mathrm{mM})$ that corresponds to $n(\mathrm{KBr}) / n\left(\mathrm{HAuCl}_{4}\right)=$ 12 is added and the mixture is shacked for additional $10 \mathrm{~min}$. Afterwards, the carbon paper piece is added and the system is shacked for $20 \mathrm{~min}$. Then, a freshly prepared $0.1 \mathrm{M}$ of AA solution as reducing agent was added dropwise, $7.62 \mathrm{~mL}$ that corresponds to $n(\mathrm{AA}) / n\left(\mathrm{HAuCl}_{4}\right)=15$. The reaction continues under the aforementioned middle-shacking and one can see the carbon paper colour turning from greyish to brown/red, characteristic of $\mathrm{Au}$. For the time dependant experiments, the reaction is quenched after $0.5,1,2$ and $4 \mathrm{~h}$. Finally, the obtained Au particles supported on carbon paper were thoroughly washed with MQ water and dried at room temperature (ca. $2 \mathrm{~h}$ ). The synthesis is fully reproducible and the overall synthesis yield was higher than $80 \%$.

$\mathrm{Au}$ @carbon paper in the presence of $\mathrm{Br}^{-}$: effect of [ $\left.\mathrm{HAuCl}_{4}\right]$. Syntheses were performed as described above by changing only the metal loading: 1, 2, 4 and $8 \mathrm{wt} \% \mathrm{Au}$.

Au@carbon paper in presence of halide ions. Syntheses were performed as described above by varying $\mathrm{Br}^{-}$and $\mathrm{I}^{-}$amount. For $\mathrm{Br}^{-}$, the synthesis was performed by increasing $\varphi=n(\mathrm{KBr}) / n\left(\mathrm{HAuCl}_{4}\right)$ from 0 to 96 while $\mathrm{HAuCl}_{4}$ is kept constant for the objective of $4 \mathrm{wt} \%$. Similar synthesis was performed using $\mathrm{KI}$ for $\varphi=n(\mathrm{KI}) / n\left(\mathrm{HAuCl}_{4}\right)=4,12,24$, 96. Finally, the syntheses in presence of $\mathrm{KCl}, \mathrm{KBr}$ and $\mathrm{KI}$ as well as control experiments using non-halide ions, $\mathrm{NO}_{3}{ }^{-}$and $\mathrm{SO}_{4}{ }^{2-}$ were run towards $8 \mathrm{wt} \% \mathrm{Au}$ (i.e., $40.0 \mathrm{mg}$ of $\mathrm{HAuCl}_{4} \cdot 3 \mathrm{H}_{2} \mathrm{O}$ ) and $\varphi=100$.

Growth of $\mathrm{Au}, \mathrm{Pd}$ and Pt particles on Toray carbon paper. The method was extended to other metals of interest, Pd and Pt for $8 \mathrm{wt} \%\left(0.4 \mathrm{mg}_{\text {metal }} \mathrm{cm}^{-2}\right)$. Pd was synthesized at $40{ }^{\circ} \mathrm{C}$ using $61.4 \mathrm{mg}$ of $\mathrm{K}_{2} \mathrm{PdCl}_{4}$ and $\varphi=n(\mathrm{KBr}) / n\left(\mathrm{~K}_{2} \mathrm{PdCl}_{4}\right)=100$ and $\mathrm{Pt}$ at $40{ }^{\circ} \mathrm{C}$ using $53.1 \mathrm{mg}$ of $\mathrm{H}_{2} \mathrm{PtCl}_{6} \cdot 6 \mathrm{H}_{2} \mathrm{O}$. For Au materials, the role of the temperature was probed for syntheses in the presence of $\mathrm{KCl}, \mathrm{KBr}$ and $\mathrm{KI}$ at $40{ }^{\circ} \mathrm{C}$. A $30 \mathrm{~min}$ reaction time was necessary for Au materials, $1 \mathrm{~h}$ for Pd and $5 \mathrm{~h}$ for Pt.

Instrumentation. UV-Vis measurements were performed using a Thermo Scientific Evolution 260 Bio UV-visible spectrophotometer. Quantitative analysis was performed by inductively coupled plasma mass spectrometry (ICP-MS, Agilent 7500ce). X-ray diffraction (XRD) analysis was conducted using a Bruker D2 Phaser diffractometer operated at $30 \mathrm{kV}$ and $10 \mathrm{mV}$ (Cu tube at $\lambda=1.53184 \AA$ ) employing nickel filter. Data were recorded from $2 \theta=20$ to $2 \theta=90^{\circ}$ at incremental step size of $0.01012^{\circ}(2 \theta)$ for a time per step of $0.6 \mathrm{~s}$ and stage rotation of 2 rpm. A JEOL JEM-2800 scanning transmission electron microscope (S/TEM) operated at $200 \mathrm{kV}$ was used for highresolution transmission electron microscopy (HRTEM), STEM, high-angle annular dark-field STEM (HAADF-STEM), secondary electron (SE) tomography and nanobeam diffraction (NBD) analyses. A FEI Quanta 600 FEG microscope was used for scanning electron microscopy (SEM/HRSEM, 10-30 keV) and energy-dispersive X-ray (EDX) analyses. To enhance the SEM/HRSEM imaging capability, a thin layer (5-10 nm) of AuPd alloy was coated on the samples. A focused ion beam dual beam (dbFIB) microscope FEI Helios NanoLab 650 (operated at 2-30 kV) was used to prepare the sample for HRTEM, HAADFSTEM, SE and NBD. The surface state characterization was performed using X-ray photoelectron spectroscopy (XPS) on a Kratos Axis Ultra DLD spectrometer equipped with a monochromatic radiation source $\mathrm{Al}$ mono (Al-K $\alpha$ : $1486 \mathrm{eV})$ operating at $15 \mathrm{kV}$ and $10 \mathrm{~mA}$. Survey spectra were collected with a step of $1 \mathrm{eV}$ (transition energy: $160 \mathrm{eV}$ ) and high-resolution XPS spectra 
were recorded at a step of $0.1 \mathrm{eV}$ (transition energy: $40 \mathrm{eV}$ ). The measurement of binding energy (BE) was corrected based on the energy of C $1 \mathrm{~s}$ at $285 \mathrm{eV}$ (Toray carbon paper) and quantifications were carried out from the corresponding XPS peak area after correction with suitable sensitivity factors from the standard CASA XPS software.

Electrochemical measurements. An electrode is cut into L-shape and coated with paraffin wax at the connecting ends to yield a square of 5 and $10 \mathrm{~mm}$ sides for cyclic voltammetry (CV) and direct glucose fuel cell (DGFC) tests, respectively. The underpotential deposition of lead $\left(\mathrm{Pb}_{\mathrm{UPD}}\right)$ experiments were performed in $0.1 \mathrm{M} \mathrm{NaOH}$ and $1 \mathrm{mM} \mathrm{Pb}\left(\mathrm{NO}_{3}\right)_{2}$ by CV from 0.8 to 0.25 $\mathrm{V} v s$. RHE (from the higher potential to the lower potential). All CV tests (blank ( $\mathrm{N}_{2}$ atmosphere), glucose electrooxidation and $\mathrm{Pb}_{\mathrm{UPD}}$ ) were conducted in a conventional three-electrode cell using a $\mathrm{CHI}$ $611 \mathrm{C}$ potentiostat (CH Instruments, Inc., U.S.A.). Saturated calomel electrode (SCE) and Pt mesh were used as reference and counter electrodes, respectively. However, all potentials were scaled herein versus the reversible hydrogen electrode (RHE). ORR experiments were carried out using a DY2300 bi-potentiostat (Digi-Ivy, Inc.) by linear sweep voltammetry (LSV) recording only the current from $\mathrm{O}_{2}$ reduction. For ORR, the solution was completely deoxygenated with $\mathrm{N}_{2}$ and $\mathrm{CV}$ was performed until steady-state at $50 \mathrm{mV} \mathrm{s}^{-1}$. Then, the solution was saturated with pure $\mathrm{O}_{2}$ before collecting ORR polarization curves at $5 \mathrm{mV} \mathrm{s}{ }^{-1}$ scan rate. DGFC tests were performed on a CHI $660 \mathrm{E}$ potentiostat (CH Instruments, Inc., U.S.A.) by recording: (i) the open circuit voltage (OCV) for $10 \mathrm{~min}$ and (ii) polarization curves by a quasisteady state galvanostatic current drawing at $0.05 \mathrm{~mA} \mathrm{~s}^{-1}$ from OCV to the cell voltage of $0.1 \mathrm{~V}$. For DGFC, a home-made twocompartment cell separated with an anion-exchange membrane (AEM, Fumasep ${ }^{\circledR}$ FAA, Fumatech) was employed.

\section{Results and discussion}

\section{Novel method for particles growth at carbon substrate}

Compared to the traditional method for particle preparation (Fig. 1a, pathway 1), the proposed approach (pathway 2) simplifies the process and post-synthetic steps into one overall route by assembling the metallic particles directly onto a carbon support. An image of the support before and after the reaction where the red colour indicates the deposition of Au particles is illustrated in Fig. 1a. In order to regulate the growth of Au particles, potassium halide precursors, $\mathrm{KX}(\mathrm{X}=\mathrm{Cl}, \mathrm{Br}, \mathrm{I})$ were added so that the ratio of $\mathrm{KX}$ to $\mathrm{Au}(\varphi)$ follows $\varphi=n(\mathrm{KX}) / n\left(\mathrm{HAuCl}_{4}\right)$. Fig. $1 \mathrm{~b}-\mathrm{d}$ highlight the colour change of $\mathrm{HAuCl}_{4}$ aqueous solutions as a function of the ratio of added $\mathrm{KX}$ to Au. This is further illustrated by UV-Vis spectra (Fig. 1e), indicating the replacement of $\mathrm{Cl}^{-}$by other halides $\mathrm{Br}^{-}$or $\mathrm{I}^{-}$to form $\left[\mathrm{AuCl}_{4-x} \mathrm{X}_{x}\right]^{-}$. Further chemical reduction of the complex in the presence of halide ions yields the nucleation and growth of NPs directly onto carbon paper.

\section{Physical structure and morphological characterization of the metal particles decorated carbon fiber paper}

Time-dependent Au particles growth on carbon paper. We first carried out a systematic study to evaluate the impact of
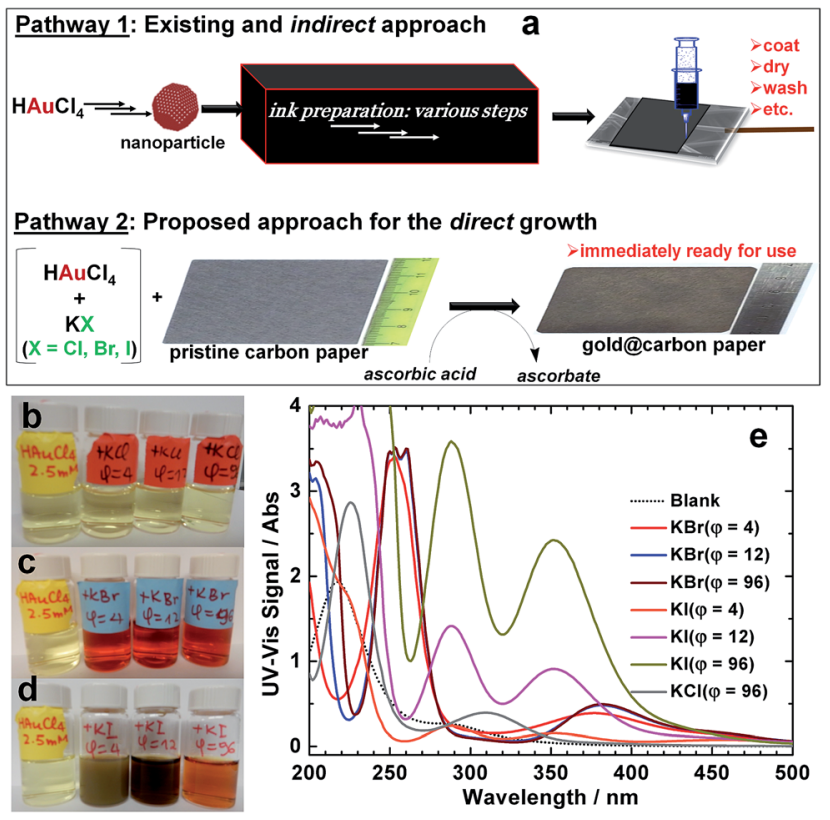

Fig. 1 Schematic illustration of the two general approaches for the modification of substrates by metallic (nano)particles. (a) Pathway 1: the traditional method that leads to particles (solution or powder), requires the preparation of an ink before the incorporation on the support; pathway 2: simplified method for the direct growth of metallic particles onto a carbon paper by a chemical method in presence of halide ions. AA: L-ascorbic acid. (b-d) From top to down: photo showing the colour change of $\mathrm{HAuCl}_{4}$ aqueous solution (fixed at $2.5 \mathrm{mM}$ ) after the addition of $\mathrm{KCl}(\mathrm{b}), \mathrm{KBr}(\mathrm{c})$ and $\mathrm{KI}$ (d) for different amount of $\varphi=n(\mathrm{KX}) / n\left(\mathrm{HAuCl}_{4}\right)$. (e) UV-Vis spectra of $\mathrm{HAuCl}_{4}$ aqueous solution (diluted 25 -times) in presence of different halides to regulate the Au particles growth.

reaction duration. We especially aimed to study the reaction following the addition of a reducing agent, ascorbic acid (AA), as that is the presumed starting point for the nucleation and growth in a seed-free solution. To this end, $\mathrm{Br}^{-}$was chosen as an additive, because $\mathrm{Cl}^{-}$already exists within the chosen starting metal salt $\mathrm{HAuCl}_{4}$ and therefore, the effects of additional $\mathrm{Cl}^{-}$were likely to be minimal. To ensure an excess of $\mathrm{Br}^{-}$ in the growth solution, a large molar ratio $(\varphi$, where $\varphi=n(\mathrm{KBr}) /$ $\left.n\left(\mathrm{HAuCl}_{4}\right)\right)$ of $12: 1$ was fixed. Indeed, considering its larger ionic radius and preferential adsorption on crystallographic facets $(h k l),{ }^{30-32}$ we hypothesized that $\mathrm{Br}^{-}$would have a greater effect on the anisotropic growth rate than $\mathrm{Cl}^{-}$. Upon addition of $\mathrm{KBr}$ in the aqueous solution of $\mathrm{HAuCl}_{4}$, the mixture instantaneously undergoes a colour change from yellow to brown, Fig. 1b-d (extended data are reported within Fig. S2a †). This transition was studied by UV-Vis measurements (Fig. 1e), which showed that the main absorption peak at $200-220 \mathrm{~nm}$ and 290-320 $\mathrm{nm}$ (assigned to the ligand-to-metal charge transfer transition phenomenon in metal complex ions ${ }^{33}$ ) disappeared while two new characteristic features appear at 253 and $380 \mathrm{~nm}$, indicating that $\left[\mathrm{AuCl}_{4}\right]^{-}$was successfully replaced by $\left[\mathrm{AuBr}_{4}\right]^{-}$ (extended UV-Vis data are reported within Fig. S2 and S3†). Upon addition of AA, the mixture turned progressively from brown to colourless, indicating that $\mathrm{Au}$ (III) was being reduced 
into the metallic state, i.e., $\mathrm{Au}^{0}$ and the previous peaks disappeared from the UV-Vis spectrum as reported in Fig. S2a and $b . \dagger$

To evaluate the influence of reaction time on the growth and subsequently the morphology of Au particles, we quenched the reaction at 0.5, 1, 2 and $4 \mathrm{~h}$ after the addition of AA. Fig. 2 depicts SEM and HRSEM micrographs for the different reaction times. After 30 minutes, AuNPs were observed by HRSEM assembling into 3D sponges-like structure with a diameter of 500-800 nm composed of 40-60 nm ultrathin 3D particles. However, longer reaction times resulted in the loss of surface features on the nanostructures. After four hours, the initial morphology deteriorated towards aggregated featureless NPs of $30-70 \mathrm{~nm}$ in diameter. The initial morphology results from the simultaneous adsorption of $\mathrm{Br}^{-}$on various crystallographic $(h k l)$ facets. Indeed, the growth rate of low-indexed Au surfaces (100), (110) and (111) is similar in the presence of $\mathrm{Br}^{-} .^{30-32}$ The continuous diffusion and reduction of $\mathrm{Au}(\mathrm{III})$ will lead to a rough surface. Previous reports have suggested that a combination of molecular oxygen and halide ions can result in oxidative etching of NPs that induces anisotropic growth and leads to the disappearance of twinned nanostructures. ${ }^{17,34,35}$ Therefore, considering the abundance of $\mathrm{Br}^{-}$in the solution as well as $\mathrm{O}_{2}$ from the air, we attributed the observed degradation of the grown AuNPs to the etching capability of $\mathrm{Br}^{-} / \mathrm{O}_{2}$ as well as $\mathrm{Cl}^{-} / \mathrm{O}_{2}$. To prevent this morphology deformation, we quench the reaction at $30 \mathrm{~min}$, unless specified elsewhere.

Particles growth on the surface of carbon paper. Suitability of NP materials for the applications mentioned above requires control of particle localization within the $3 \mathrm{D}$ structure of carbon paper. SEM micrographs of carbon surfaces containing AuNPs (Fig. 3a) demonstrate that the particles were primarily deposited onto the fibers' surface when $4 \mathrm{wt} \%$ $\mathrm{Au}$ was used. By doubling the amount of $\mathrm{Au}$, no significant $\mathrm{Au}$ deposition inside the carbon paper occurs (Fig. 3a-d), suggesting that NPs are preferentially being deposited onto the carbon surface. As for the case of carbon black, the reduction of metal salt takes place at the external fibers' surface. Then, the formation of the first seed layer of particles acts as an active site where further reduction occurs. Therefore, the salts within the carbon paper interior diffuse towards the surface

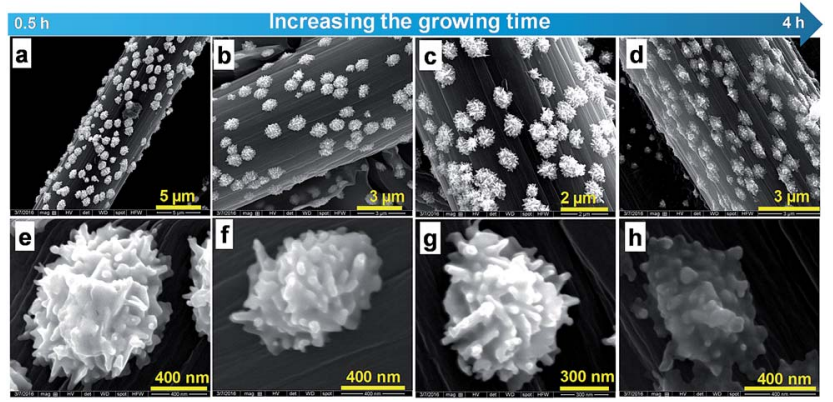

Fig. 2 Au particles growth on Toray carbon paper (in the presence of $\mathrm{Br}^{-}$) with $n(\mathrm{KBr}) / n\left(\mathrm{HAuCl}_{4}\right)=12$ and $4 \mathrm{wt} \% \mathrm{Au}$. SEM/HRSEM images for different reaction time: (a and e) $0.5 \mathrm{~h}$, (b and f) $1 \mathrm{~h}$, (c and g) $2 \mathrm{~h}$, (d and h) $4 \mathrm{~h}$.

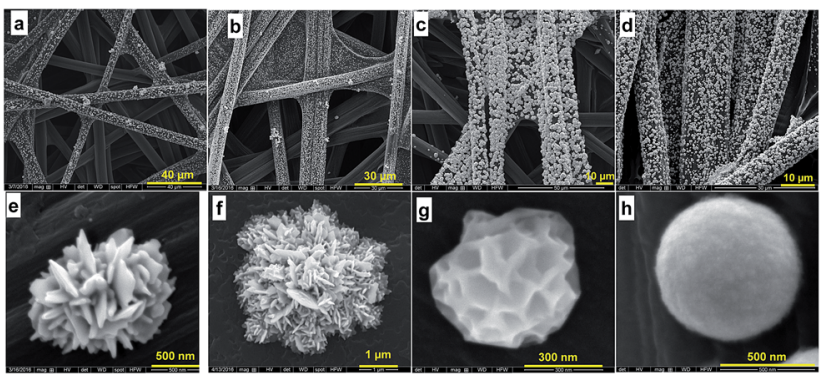

Fig. 3 (a-d) SEM and (e-h) HRSEM micrographs of metallic particles growth on Toray carbon paper. Au for $n(\mathrm{KBr}) / n\left(\mathrm{HAuCl}_{4}\right)=100: 4 \mathrm{wt} \%$ (a and e) and $8 \mathrm{wt} \%$ (b and f) at room temperature. (c and g) Pd for $n(\mathrm{KBr}) / n\left(\mathrm{~K}_{2} \mathrm{PdCl}_{4}\right)=100$ and 8 wt $\%$ at $40{ }^{\circ} \mathrm{C}$. (d and h) Pt for $8 \mathrm{wt} \%$ at $40^{\circ} \mathrm{C}$.

where they are reduced by AA onto the existing metal particles.

To elucidate the role of larger halide ions $\mathrm{X}^{-}(\mathrm{X}=\mathrm{Br}$, I) on AuNP growth, various amounts of each halide were introduced in the form of $\mathrm{KX}$, where the relative amount of $\mathrm{X}^{-}$to $\mathrm{Au}$ is described as $\varphi=n(\mathrm{KX}) / n\left(\mathrm{HAuCl}_{4}\right)$. The standard redox potentials of the involved $\mathrm{Au}(\mathrm{I})$ and $\mathrm{Au}(\mathrm{III})$ halides, the dissociation constants of $\mathrm{Au}$ (III) halide at $25{ }^{\circ} \mathrm{C}$, and the standard redox potentials of the involved metal complexes with halides within Tables S1-S $3 \uparrow$ demonstrate that the addition of $\mathrm{X}^{-}$, will result in the conversion of $\left[\mathrm{AuCl}_{4}\right]^{-}$into mixed-ion complexes that evolve towards the more stable $\left[\mathrm{AuX}_{4}\right]^{-}$in the presence of ionic ligand $\mathrm{X}^{-}$. Otherwise, the mixed ion-complex $\left[\mathrm{AuCl}_{4-x} \mathrm{X}_{x}\right]^{-}$, with $0<x$ $\leq 4$, is obtained according to eqn (1).

$$
\left[\mathrm{AuCl}_{4}\right]_{(\mathrm{aq})}{ }^{-}+x \mathrm{KX}_{(\mathrm{aq})} \rightarrow\left[\mathrm{AuCl}_{4-x} \mathrm{X}_{x}\right]_{(\mathrm{aq})}{ }^{-}+x \mathrm{KCl}_{(\mathrm{aq})}
$$

Since the ionic radii $(r)$ of $\mathrm{I}^{-}$and $\mathrm{Br}^{-}\left(r\left(\mathrm{I}^{-}\right)=220 \mathrm{pm}\right.$ and $\left.r\left(\mathrm{Br}^{-}\right)=195 \mathrm{pm}\right)$ are larger than their counterpart chloride $\left(r\left(\mathrm{Cl}^{-}\right)=181 \mathrm{pm}\right)$, the partial or total substitution of $\mathrm{Cl}^{-}$by $\mathrm{X}^{-}$is expected to accentuate the steric hindrance around the metal cation, which will further control the seed growth, similar to that observed in the presence of carbon black. ${ }^{36}$ Fig. S5-S7† show (HR)SEM images for NPs grown using $\mathrm{Br}^{-}$or $\mathrm{I}^{-}$solutions where $\varphi=0,2,4,24$ and 96 . These results indicate that anisotropic growth and control of particle distribution on the support depend on excess amounts of $\mathrm{X}^{-}$in the solution. Indeed, according to eqn (1), $\varphi=4$ corresponds to an equivalent replacement of $\mathrm{Cl}^{-}$by $\mathrm{X}^{-}$. However, SEM images of NPs prepared with solutions where $\varphi=4$ (Fig. S5c, S5g, S6a and b†) show few of the expected morphological features, suggesting that an excess of halide ions is required. Indeed, HRSEM images of NPs prepared from solutions of $\mathrm{Br}^{-}$where $\varphi=96$ (Fig. 3e and f) reveal intricate 3D microstructures composed of hundreds of NPs. The slats protruding from these structures are 5-10 nm thick and tens of square micrometers across each face. However, HRSEM images of NPs grown in solutions containing a large excess of $\mathrm{I}^{-}$(Fig. S5i-k and S7 $\dagger$ ), reveal the self-assembly of AuNPs to form leaf crystals. Taken together, these results suggest that the rapid anisotropic growth of Au particles results from preferential adsorption of $\mathrm{X}^{-}$at primary NPs, and that 
these adsorption sites act as "seeds" for growth in different directions. We further performed control syntheses to determine whether the anisotropy can be influenced by the nature of other transition metals, $\mathrm{Pd}$ and Pt. Pd enables obtaining microstructures exhibiting higher exposed surface area because of the presence of many defects as can be seen in Fig. 3c and $\mathrm{g}$. Pt material is composed of microspheres $\approx 200-600 \mathrm{~nm}$ diameter decorating homogeneously the entire external surface of each fiber (Fig. 3d and h). To better support the role of halides, we performed control experiments at $8 \mathrm{wt} \%$ using halides (HRSEM images within Fig. S8 $\dagger$ ) and other ions, i.e., $\mathrm{NO}_{3}{ }^{-}$and $\mathrm{SO}_{4}{ }^{2-}$ (HRSEM images within Fig. $\mathrm{S} 9 \dagger$ ). Both non-halide ions lead to 200-400 nm microspheres even if $\mathrm{NO}_{3}{ }^{-}$leads to rougher surface. The control syntheses of $\mathrm{Au}$ at $40{ }^{\circ} \mathrm{C}$ in absence of $\mathrm{X}^{-}$(HRSEM images within Fig. S10 $\dagger$ ) and its presence (HRSEM images within Fig. S11-S13†) substantiate the main role of the halides. These results underpin completely the role of the halides on the morphological control of the gold crystals growth.

Parameters affecting the formation of anisotropic Au particles on carbon. The previous results demonstrate that we were able to manipulate the synthesis towards different morphologies. Fig. 4 shows the experimental parameters, which enable an effective control of the morphology. From the previous outcomes, we excluded any major role of the $\mathrm{K}^{+}$on the formation of anisotropic Au particles. We first observed that by increasing the $\mathrm{Br}^{-}$amount, the shape of the particles switches from the sponge-like undefined surface (Fig. 4a) to a well established morphology (Fig. 4b). This suggests that the reduction of the precursor in the presence of minimal $\mathrm{Br}^{-}$ ensure prompt addition of atoms and growth towards a pristine morphology. Then, the chemisorption of remaining excess $\mathrm{Br}^{-}$ on the previous material promotes the formation of specific elementary facets. Finally, the localized controlled oxidative etching will initiate the preferential growth. $\mathrm{Cl}^{-}$from the initial metal salt leads to a $\mathrm{Cl}^{-} / \mathrm{O}_{2}$ etchant. ${ }^{3,37}$ However, the most etchant is $\mathrm{Br}^{-} / \mathrm{O}_{2}$ since the raise of $\mathrm{Br}^{-}$amount is accompanied by an increase of the oxidative etching capability. However, $\mathrm{I}^{-}$ induced the formation of larger particles (Fig. 4c) because of the fast growth. By varying the concentration of the metal salt in the solution that goes from $2.5 \mathrm{mM}$ ( $4 \mathrm{wt} \% \mathrm{Au}$, Fig. $4 \mathrm{~b}$ and c) to

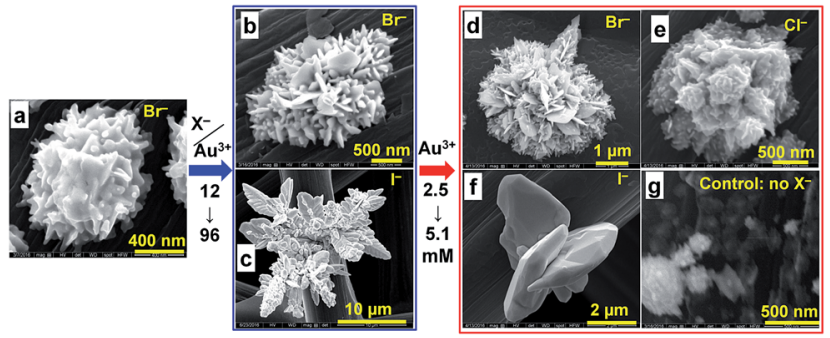

Fig. 4 HRSEM micrographs for the Au particles morphology evolution for initial solution containing: (a) $\mathrm{Br}^{-}$for $\varphi=12$ and $4 \mathrm{wt} \%$, (b) $\mathrm{Br}^{-}$for $\varphi$ $=96$ and 4 wt\%; (c) $I^{-}$for $\varphi=96$ and $4 \mathrm{wt} \%$; (d) $\mathrm{Br}^{-}$for $\varphi=100$ and 8 wt\%; (e) $\mathrm{Cl}^{-}$for $\varphi=100$ and $8 \mathrm{wt} \%$; (f) $\mathrm{I}^{-}$for $\varphi=100$ and $8 \mathrm{wt} \%$; (g) control in absence of halides. The reaction time is 30 minutes at room temperature.
$5.1 \mathrm{mM}$ ( $8 \mathrm{wt} \% \mathrm{Au}$, Fig. $4 \mathrm{~d}-\mathrm{f}$ ), the number of the building blocks increases promptly provided the molar ratio of $\mathrm{X}^{-}$is kept unchanged. This number increase of the building blocks is logically accompanied by the size of the $3 \mathrm{D}$ microstructures. The roughest surface is obtained by employing $\mathrm{Br}^{-}$. Fig. $4 \mathrm{~g}$ shows SEM of the control synthesis without introducing any halide (no formation of well defined morphology) and endorses the halide anions role as cornerstone for controlling the morphology of Au particles.

Compositional and surface characterizations of $\mathrm{Au}$ particles growth on carbon paper. Having demonstrated the ability to use various halides to grow NPs directly onto a carbon support, we sought to study the surface composition and morphology more carefully. EDX analysis (Fig. 5a) of Pt, Pd, Au based materials as well as a blank carbon surface for comparison, qualitatively confirms the presence of the metals within the supporting substrate. From the XRD patterns in Fig. 5b (using different halides) and Fig. S14a $\uparrow$ (different amount of $\mathrm{KBr}$ ), the peak localized at $25^{\circ}$ corresponds to carbon support, as previously observed from EDX. Those situated at $38.1^{\circ}, 44.3^{\circ}, 64.5^{\circ}$ and $77.5^{\circ}$ correspond, respectively, to the crystallographic planes (111), (200), (220) and (311) of face-centred cubic (fcc) of Au. The high-resolution XPS spectra of $\mathrm{Au} 4 \mathrm{f}$ region is depicted in Fig. $5 \mathrm{c}$ (using different halides) and Fig. S14b $\dagger$ (various amount of $\mathrm{KBr}$ ). In agreement with EDX and XRD analyses, XPS measurements underscore important current trends that the obtained metals are not oxidized. The doublet of gold metal are situated at $83.8 \mathrm{eV}$ for $\mathrm{Au} 4 \mathrm{f}_{7 / 2}$ and $87.5 \mathrm{eV}$ for $\mathrm{Au} 4 \mathrm{f}_{5 / 2}$. The inset shows that $\mathrm{Br}^{-}$and $\mathrm{NO}_{3}{ }^{-}$lead to more exposed atoms at the surface of particles since the surface atomic (left $y$-axis) and weight (right
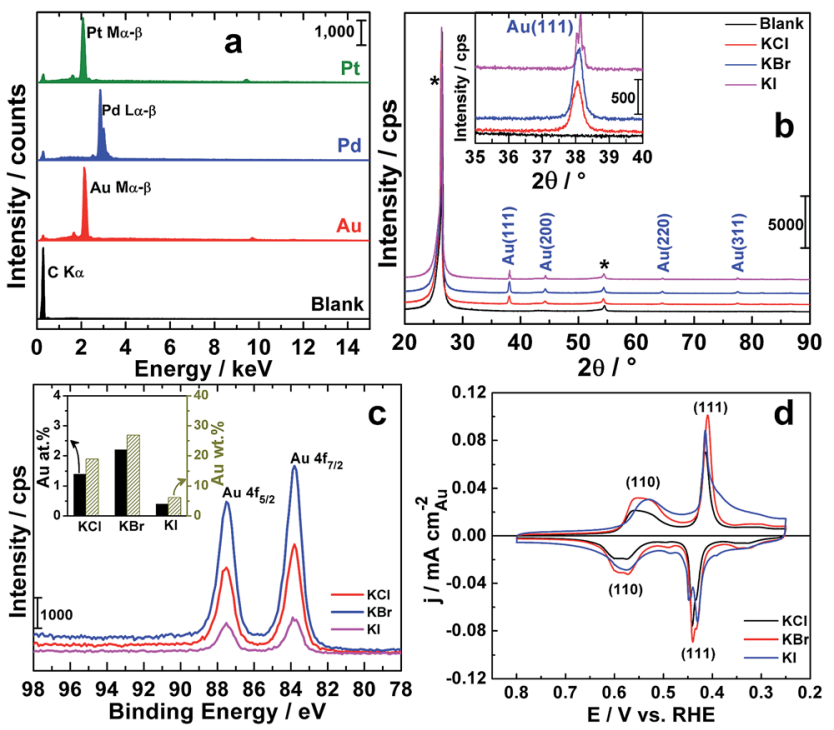

Fig. 5 Compositional, structural and surface characterizations of metallic particles growth on Toray carbon paper with metal loading of $8 \mathrm{wt} \%$. (a) EDX, (b) XRD patterns of Au (synthesis in presence of $\mathrm{I}^{-}, \mathrm{Br}^{-}$, $\mathrm{Cl}^{-}$): inset shows the patterns for Au (111) crystallographic plane and (c) high-resolution XPS spectra of the Au 4 f core level: inset shows the surface atomic (at\%: left $y$-axis) and weight (wt\%, right $y$-axis) compositions of Au. (d) UPD of lead of Au electrodes in $0.1 \mathrm{M} \mathrm{NaOH}+1$ $\mathrm{mM} \mathrm{Pb}\left(\mathrm{NO}_{3}\right)_{2}$ at $20 \mathrm{mV} \mathrm{s}^{-1}$. 
$y$-axis) compositions are higher due to the particles morphology, supported by HRSEM results. Such results are expected to enhance the catalytic performances of the as-prepared materials.

\section{Electrochemical performance}

Next we aimed to study the newly described NP materials as electrode materials. We investigated the electrocatalytic properties by considering two model reactions in alkaline medium. Prior to that, we first compared the responses of the electrodes in $\mathrm{CV}$ using a model of $\mathrm{Pb}_{\mathrm{UPD}}$, which has proved its efficiency for characterizing the surface of metallic nanostructures, as well as for the assessment of the crystallographic structure.

Fig. S14c $\dagger$ depicts the recorded CVs in $0.1 \mathrm{M} \mathrm{NaOH}$ showing well defined electrochemical characteristics of Au. Fig. 5d and $\mathrm{S} 14 \mathrm{~d}$ and $\mathrm{e} \dagger$ depict the $\mathrm{Pb}_{\mathrm{UPD}}$ for different electrodes exhibiting the same overall behaviour. Starting at $0.8 \mathrm{~V} v s$. RHE and sweeping the potential down, two reduction peaks appear at 0.55 and $0.41 \mathrm{~V} v$ s. RHE, which are typically attributed to the deposition of lead on (110) and (111) Au facets, respectively. ${ }^{38}$ Similarly, the two stripping peaks at 0.45 and $0.58 \mathrm{~V} v$ s. RHE recorded during the positive scan are basically assigned to a reversible desorption of the previous $\mathrm{Pb}$ layer on (111) and (110) Au facets, respectively. It is worth noting that the slight shift of the above peaks compared to common observations ${ }^{38}$ and the duplication of (111) could be assigned to the presence of high-index $(h k l)$ facets and/or defects. As shown within Fig. S14e, $\dagger$ a close examination reveal the presence of (100) facets, which are known to display high activity towards glucose oxidation..$^{38,39}$ The presence of these low-coordination number (100), (110) and (111) is expected to enhance the catalytic properties of $\mathrm{Au}$ materials. Importantly, the obtained results greatly support the above hypothesis of Au particles growth at different $(h k l)$ directions leading to various facets.

We next evaluated the electrocatalytic properties of $\mathrm{Au}, \mathrm{Pd}$ and Pd materials for ORR in $0.1 \mathrm{M} \mathrm{NaOH}$ (Fig. 6a) while the steady-state blank CVs are reported in Fig. S15. $\uparrow$ Note that the convention used to plot the current-potential curves corresponds to a positive reduction current and a negative oxidation current. As shown within the inset, the results reveal that ORR occurs at $\mathrm{Pt}$ electrodes at $c a .1 .1 \mathrm{~V} v s$. RHE, ultimately approaching the theoretical equilibrium potential of $1.18 \mathrm{~V} v s$. RHE. Pd electrode shows better ORR performances for $E \geq 0.8 \mathrm{~V}$ $v s$. RHE that comes from the availability of hydroxyl species, the main ORR performance descriptors. Overall, the outcomes indicate that Au material is not an efficient cathode electrode while Pt and Pd aspire to be potential active cathodic electrocatalysts for ORR.

The electrocatalytic activity of the as-prepared Au-based materials was then studied for glucose $(10 \mathrm{mM})$ electrooxidation in $0.1 \mathrm{M} \mathrm{NaOH}$. Among our investigated parameters during the synthesis of $\mathrm{Au}$ materials using the halide $\mathrm{Br}^{-}$, a ratio $\varphi=n(\mathrm{KBr}) / n\left(\mathrm{HAuCl}_{4}\right)$ of 96 gives the best performances in terms of activity and stability (CV within Fig. S16at). This outcome substantiates the SEM results (Fig. S5 $\dagger$ ), the rough surface provides more active sites for the reaction. Fig. $6 \mathrm{~b}$ and
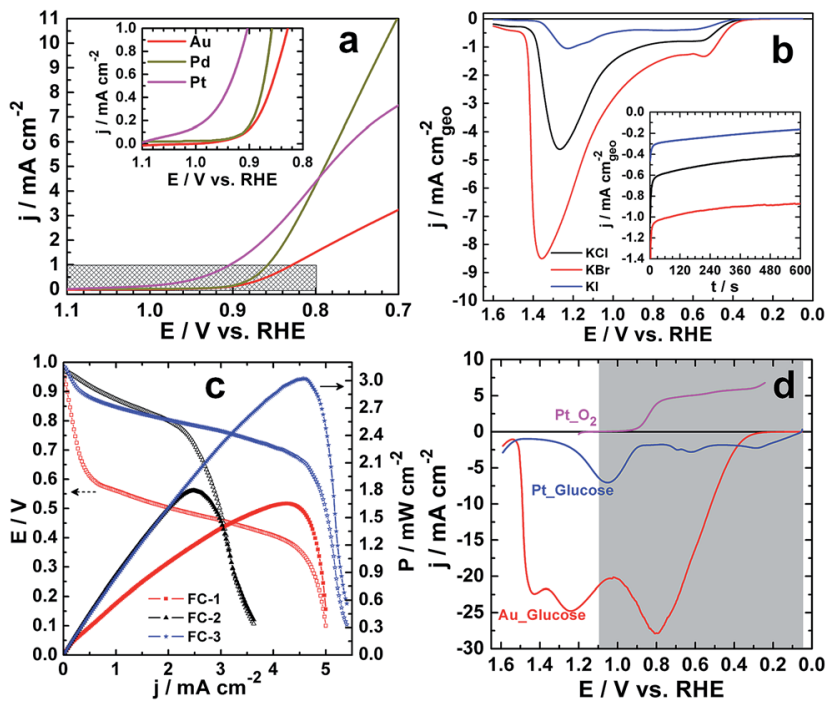

Fig. 6 Electrochemical characterization of the as-synthesized materials for the metal loading of $8 \mathrm{wt} \%$ (i.e. $0.4 \mathrm{mg}_{\text {metal }} \mathrm{cm}^{-2}$ ). (a) Positivegoing ORR polarization curves (insets show the dashed region) recorded at $\mathrm{Au}, \mathrm{Pd}$ and $\mathrm{Pt}$ materials at $5 \mathrm{mV} \mathrm{s}^{-1}$ in $\mathrm{O}_{2}$-saturated $0.1 \mathrm{M}$ $\mathrm{NaOH}$ aqueous solution. (b) Voltammograms for glucose (10 mM) oxidation at Au materials in $0.1 \mathrm{M} \mathrm{NaOH}$ at $50 \mathrm{mV} \mathrm{s}^{-1}$ : inset shows the chronoamperometry curves recorded at $0.65 \mathrm{~V}$ vs. RHE. (c) Fuel cell polarization curves (iR-uncorrected): the Pt cathode $\left(1 \mathrm{~cm}^{2}\right)$ operated in $0.5 \mathrm{M} \mathrm{NaOH}+\mathrm{O}_{2}$; the Au anode $\left(1 \mathrm{~cm}^{2}\right.$ for $\left.\mathrm{FC}-1\right)$, Pt anode $\left(1 \mathrm{~cm}^{2}\right.$ for FC-2) and Pt anode ( $2 \mathrm{~cm}^{2}$ for FC-3) operated in $0.5 \mathrm{M} \mathrm{NaOH}+0.3 \mathrm{M}$ glucose; a Fumatech AEM separated both compartments. (d) Voltammetry polarization curves recorded in $0.5 \mathrm{M} \mathrm{NaOH}$ for $\mathrm{O}_{2}$ reduction (upper) and glucose (0.3 M) electrooxidation (lower).

$\mathrm{S} 16 \mathrm{~b} \dagger$ highlight high catalytic activity of the material synthesized in the presence of $\mathrm{Br}^{-}$compared to $\mathrm{Cl}^{-}$and $\mathrm{I}^{-}$. For $0.1 \mathrm{M}$ glucose (Fig. S16c $\dagger$ ), an enhanced peak current density $j_{\text {peak }}$ of $14 \mathrm{~mA} \mathrm{~cm}$ geo $^{-2}$ is reached. From Fig. $6 \mathrm{~b}$ and S16d-f, $\uparrow$ the chronoamperometry curves recorded at $0.65 \mathrm{~V} v$ s. RHE show that $\mathrm{Br}^{-}$enables obtaining a stable electrocatalyst that is 2 - and 5 -fold higher than $\mathrm{Cl}^{-}$and $\mathrm{I}^{-}$, respectively. The high activity of the material obtained with $\mathrm{Br}^{-}$is rationally ascribed to its structure, especially the presence of different defects that lead to high surface area. Otherwise, Fig. $6 \mathrm{~b}$ shows that Au electrodes exhibits improved kinetics (the reaction starts at $E \leq 0.3 \mathrm{~V} v s$. RHE) with $c a .100 \mathrm{mV}$ shift towards lower electrode potentials compared to their counterparts in literature ${ }^{20,24}$ which is a good indicator for future application as anode material. Importantly, the peak current density is at least 2-fold higher while the present Au weight is only $4 \mathrm{wt} \%$ compared to $30 \mathrm{wt} \%$ for electrospinning ${ }^{24}$ and low loading of $0.4 \mathrm{mg}_{\text {metal }} \mathrm{cm}^{-2}$ compared to $3 \mathrm{mg}_{\text {metal }} \mathrm{cm}^{-2}$ for electrodeposition. ${ }^{20}$ In other words, the present carbon paper based Au materials exhibit highly enhanced activity with very low Au amount that is 7 -fold lower than the literature. Furthermore, Fig. S15a $\uparrow$ demonstrates that the achieved peak current density of $9 \mathrm{~mA} \mathrm{~cm}_{\mathrm{Au}}{ }^{-2}$ is higher than the conventional chemically synthesized AuNPs by an order of magnitude ${ }^{38}$ Thus, using the as-synthesized bromide-regulated particles growth, for instance Au (having rough surface) as anode for glucose oxidation should enable designing an efficient DGFC. 

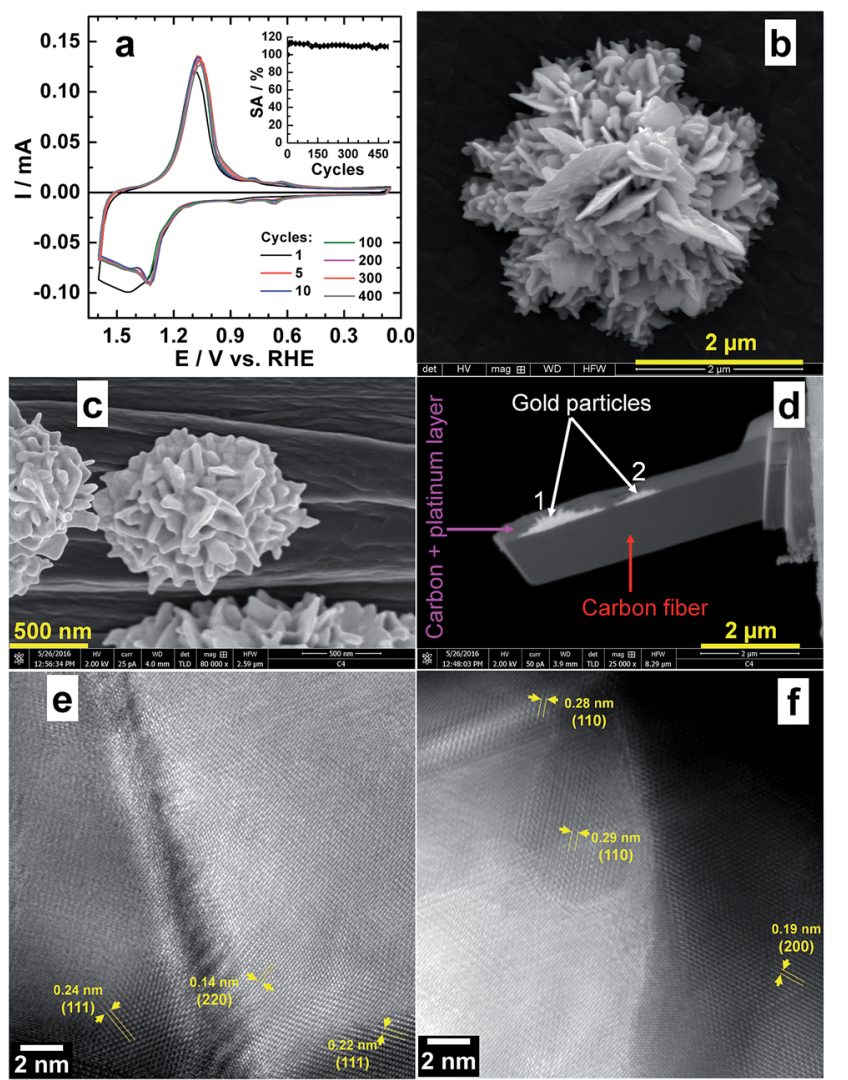

Fig. 7 ( $a$ and b) Electrochemical durability tests of Au particles growth on Toray carbon paper for $n(\mathrm{KBr}) / n\left(\mathrm{HAuCl}_{4}\right)=100$ and $8 \mathrm{wt} \% \mathrm{Au}$ : (a) CVs between $0.05-1.6 \mathrm{~V}$ vs. RHE at $50 \mathrm{mV} \mathrm{s}^{-1}$ in $0.1 \mathrm{M} \mathrm{NaOH}$ (inset: SA decay) and (b) HRSEM micrograph of aged material after 500 cycles. (c) HRSEM micrograph taken during the sample preparation by dbFIB, (d) SEM image of the as-prepared sample by dbFIB and (e and f) atomicresolution HRTEM images showing the different atom arrangements.

Finally, we tested the cell performance employing the assynthesized $\mathrm{Pt}$ as cathode and $\mathrm{Au}$ (from $\mathrm{KBr}$ ) or $\mathrm{Pt}$ as anode electrodes, respectively. The polarization and power density curves are presented in Fig. 6c. A high OCV of $1.01 \pm 0.02 \mathrm{~V}$ indicates that both electrodes have good kinetics, which is higher than OCV of $0.64 \mathrm{~V}$ for electrodes obtained from electrodeposition method. ${ }^{20}$ Using $\mathrm{Au}$ as anode, the present DGFC exhibits a peak power density of $1.7 \pm 0.1 \mathrm{~mW} \mathrm{~cm}^{-2}$, which is higher than relevant reported values that range from 0.6 to $1.5 \mathrm{~mW} \mathrm{~cm}^{-2}$ (see Table 5 $\uparrow$ for relevant DGFCs from literature). By increasing the Pt anode surface area from 1 to $2 \mathrm{~cm}^{2}$, a record value of $3.1 \pm 0.1 \mathrm{~mW} \mathrm{~cm} \mathrm{~cm}^{-2}$ is obtained at $0.7 \mathrm{~V}$ cell voltage without any fuel circulation, which is higher than the reported power densities of previously reported $\mathrm{Pt} / \mathrm{C}$ and $\mathrm{Au} / \mathrm{C}$ materials. $^{40}$ In $1 \mathrm{M} \mathrm{KOH}$, a DGFC using the state-of-the-art commercial PtRu/C (60 wt\%, Johnson Matthey) anode material $\left(3 \mathrm{mg}_{\text {metal }} \mathrm{cm}^{-2}\right.$ ) yields $1.38 \mathrm{~mW} \mathrm{~cm}^{-2}$ at $0.51 \mathrm{~V}(\mathrm{OCV}=0.91 \mathrm{~V})$ and $1.08 \mathrm{~mW} \mathrm{~cm}^{-2}$ at $0.50 \mathrm{~V}(\mathrm{OCV}=0.90 \mathrm{~V})$ using 0.2 and $0.3 \mathrm{M}$ glucose at $30{ }^{\circ} \mathrm{C}$, respectively. ${ }^{\mathbf{4 1}}$ The superior performance of the materials obtained here is explained by the absence of any organic contaminants or protective ligands on the surface of the metal, the good interaction between metal and support, and the particular morphology of the particles. To explain the difference between Pt and Au anodes, voltammetric curves were recorded in $0.5 \mathrm{M} \mathrm{NaOH}$ (Fig. 6d). For the same electrode size (anode and cathode), the results indicate that the DGFC performances are limited by the glucose activation at lower current densities for $\mathrm{Au}$ anode; at higher current densities, both anode and cathode are limiting in the case of Pt anode. The estimated ohmic resistance from the fuel cell polarization curves (fitting the ohmic loss region by a linear model, Fig. S17†) highlights a relatively small resistance $\left(40-80 \Omega \mathrm{cm}^{2}\right)$, i.e., good conductivity. For comparison, the value of $40 \Omega \mathrm{cm}^{2}(\mathrm{Au}=$ anode and $\mathrm{Pt}=$ cathode) is smaller than the value of $45 \Omega \mathrm{cm}^{2}$ that can be estimated from the conventional Pt/Vulcan and Au/Vulcan materials used in direct glucose fuel cell. ${ }^{40}$

\section{Electrochemical durability and textural analysis of Au particles}

We also evaluated the long-term electrochemical stability of the $\mathrm{Br}^{-}$regulated $\mathrm{Au}$ particles growth on Toray carbon paper through an accelerated durability test. The goal was to evaluate the impact of the electrochemical treatment (potential cycling from 0.05 to $1.6 \mathrm{~V} v s$. RHE at $50 \mathrm{mV} \mathrm{s}^{-1}$ in $0.1 \mathrm{M} \mathrm{NaOH}$ for a total of 1000 segments) of the evolution of the obtained structure. Fig. 7a shows the recorded voltammograms and depicts the general behaviour of $\mathrm{Au}$ and the active surface area (SA) decay. The electrode exhibits good electrochemical stability, fully supported by the post-reaction HRSEM analyses (Fig. 7b) which do not show any morphology modification.

To gain deeper insights about the structural and textural features of the as-prepared materials, a representative sample is prepared by focused ion beam dual beam (dbFIB). Fig. 7c depicts the HRSEM micrograph taken during the sample preparation by dbFIB. Protective thin layers of carbon and platinum were deposited before cutting the sample. SEM image of as-prepared sample by dbFIB is displayed within Fig. 7d showing two Au particles. Fig. 7e and f shows HRTEM images taken at different places. The presence of low and high indexes (110), (111), (200) and (220) as well as various defects and twins confirms that the sample have several NPs growing a different directions. This atomic-resolution analysis fully substantiates the previous electrochemical characterizations by $\mathrm{Pb}_{\mathrm{UPD}}$.

Next, electron diffraction studies were undertaken to confirm the crystallinity of the sample already revealed by XRD. Fig. 8a shows the NBD pattern, mainly composed of small spots making up rings and testifies the polycrystalline structure of $\mathrm{Au}$, containing various facets, (111), (200), (200), (311), etc. However, the bright spots in the center originate from the textured grains that had preferential (100) and (110) orientations during the analysis. Furthermore, the measured interplanar space for all lattice fringes roughly corresponded to those of XRD and interatomic distance values obtained from HRTEM. These NBD results endorse the multi-facet and multi-twin nature of the $\mathrm{Au}$ material synthesized in presence of $\mathrm{Br}^{-}$.

We finally combined various tomography techniques to establish the topological structure of the different areas of the sample. SE images within Fig. $8 \mathrm{~b}$ and $\mathrm{c}$ show the landforms with 


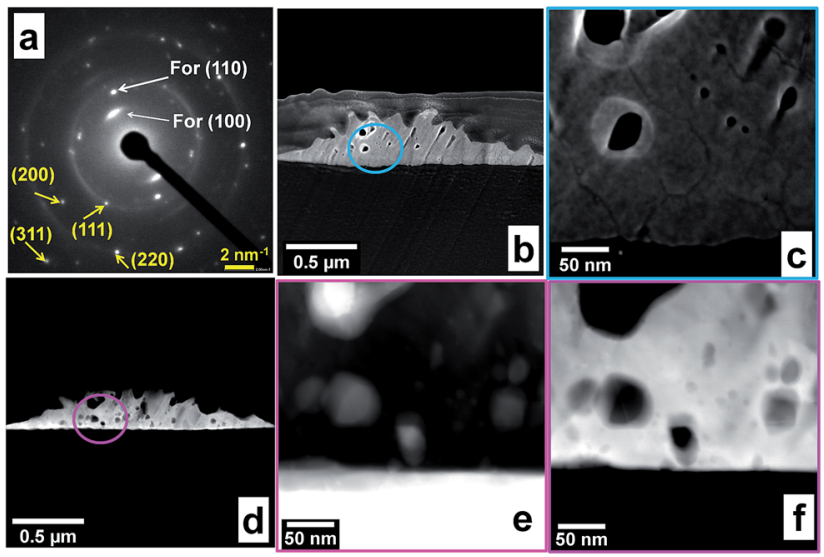

Fig. 8 Structural and textural characterizations of Au particle growth on Toray carbon paper (in the presence of $\mathrm{Br}^{-}$) for $n(\mathrm{KBr}) / n\left(\mathrm{HAuCl}_{4}\right)=$ 100 and 8 wt\%: (a) NBD patterns, (b and c) SE images, (e) bright-field STEM images, (d and f) HAADF-STEM images.

different defects and holes (dark spots). Dark-field (HAADF) STEM tomography (Fig. 8d and f) and high resolution brightfield STEM (Fig. 8e) of selected regions confirms the evidence of stress, strain and hole within $\mathrm{Au}$ nanocrystallites. Deep comparison by complementary bright-field STEM (dark regions represent the heavier element, that is Au) and HAAD-STEM (the bright represent $\mathrm{Au}$ ) images reveal that each particles has holes and the density of gold atoms is heterogeneous confirming the formation of particles with a rough surface. All these results support the high catalytic performances of the materials obtained in presence of $\mathrm{Br}^{-}$as regulator for the morphology control.

\section{Conclusions}

In summary, a novel class of electrode materials composed of carbon paper decorated by metallic particles was fabricated for both electrocatalytic oxygen reduction (ORR) and glucose oxidation reactions in alkaline medium. In this contribution, we demonstrated that the direct formation of anisotropic gold and palladium at the surface of carbon paper is feasible and can be regulated by the introduction of different halides $\left(\mathrm{Cl}^{-}, \mathrm{Br}^{-}\right.$ and $\mathrm{I}^{-}$) during nanoparticle (NP) growth. This enables bypassing the use of any Nafion binder during the electrode preparation and minimized the particle detachment during the reaction, which was fully supported by the post-reaction analysis by scanning electron microscopy. Since the metal particles are directly assembled onto the carbon paper, there is no need to prepare a catalytic ink and the developed approach allows simplifying the membrane-electrode-assembly (MEA). Then, we thoroughly determined the main parameters that enable tuning the particles growth kinetics. By fine-tuning the experimental conditions (ions, concentrations, temperature), we were able to generate different materials of $\mathrm{Au}, \mathrm{Pd}$ and $\mathrm{Pt}$ structures having various roughness and distinguished electrocatalytic properties. The carbon paper decorated by Pt particles shows distinguished electrochemical kinetic towards ORR in an alkaline medium, starting at $1.1 \mathrm{~V} v s$. RHE, ultimately approaching the theoretical equilibrium potential of $1.18 \mathrm{~V} v s$. RHE. For glucose electrooxidation, the use of $\mathrm{Br}^{-}$as regulator enables obtaining $\mathrm{Au}$ materials with rough surface leading to a record peak current density close to $10 \mathrm{~mA} \mathrm{~cm} \mathrm{Au}^{-2}$, which is higher than the conventional chemically synthesized AuNPs by an order of magnitude. All these high performances result from the particular morphology of the particles and the simplicity of the developed method. Moreover, the constructed glucose fuel cell has an outstanding open-circuit voltage (OCV) of $1.0 \mathrm{~V}$ and delivers a maximum power of $3.1 \mathrm{~mW} \mathrm{~cm} \mathrm{~cm}^{-2}$ (at high cell voltage of $0.7 \mathrm{~V}$ without any fuel circulation at room temperature with metal loading of $0.35 \mathrm{mg} \mathrm{cm}^{-2}$ ), which surpasses the relevant reported data as well as the commercial $60 \mathrm{wt} \% \mathrm{PtRu} / \mathrm{C}$ anode ${ }^{41}$ $\left(1.38 \mathrm{~mW} \mathrm{~cm}^{-2}\right.$ at $0.51 \mathrm{~V}$, OCV of $0.91 \mathrm{~V}$ using a high metal loading of $3 \mathrm{mg} \mathrm{cm}^{-2}$ ). To date, this work constitutes the first proof that metallic particles can be directly assembled onto large surface (i.e. $5 \mathrm{~cm} \times 5 \mathrm{~cm}$ ) of conducting carbon paper electrode (currently used in fuel cell technology) by means of a chemical reduction method to used as effective electrocatalysts for ORR, organic molecule oxidation and high-performance fuel cell construction with low metal content. Owing to these unique outcomes, it is believed that this work will offer a new strategic approach for simplifying the design of electrocatalysts, and pave a pathway for the breakthroughs in the development of alcohol-based fuel cell technology to achieve superior cell performances.

\section{Acknowledgements}

This work was supported by the US Army Research Office MURI (\#W911NF1410263). For the materials characterization by Scanning Transmission Electron Microscope (S/TEM: JEOL JEM-2800) and Focused Ion Beam Dual Beam Microscopy (dbFIB, FEI Helios NanoLab 650), these works made use of University of Utah USTAR shared facilities support, in part, by the MRSEC Program of NSF under Award No. DMR-1121252. We thank Prof. Boniface K. Kokoh (University of Poitiers, France) for providing the anion exchange membrane (AEM).

\section{References}

1 T. Bian, H. Zhang, Y. Jiang, C. Jin, J. Wu, H. Yang and D. Yang, Nano Lett., 2015, 15, 7808-7815.

2 V. Mazumder, M. Chi, K. L. More and S. Sun, Angew. Chem., Int. Ed., 2010, 49, 9368-9372.

3 X. Huang, Z. Zhao, Y. Chen, E. Zhu, M. Li, X. Duan and Y. Huang, Energy Environ. Sci., 2014, 7, 2957-2962.

4 P. Strasser, S. Koh, T. Anniyev, J. Greeley, K. More, C. Yu, Z. Liu, S. Kaya, D. Nordlund, H. Ogasawara, M. F. Toney and A. Nilsson, Nat. Chem., 2010, 2, 454-460.

5 J. Greeley, I. E. L. Stephens, A. S. Bondarenko, T. P. Johansson, H. A. Hansen, T. F. Jaramillo, J. Rossmeisl, I. Chorkendorff and J. K. Nørskov, Nat. Chem., 2009, 1, 552-556.

6 H. A. Miller, M. Bevilacqua, J. Filippi, A. Lavacchi, A. Marchionni, M. Marelli, S. Moneti, W. Oberhauser, 
E. Vesselli, M. Innocenti and F. Vizza, J. Mater. Chem. A, 2013, 1, 13337-13347.

7 B. Jiang, C. Li, J. Henzie, T. Takei, Y. Bando and Y. Yamauchi, J. Mater. Chem. A, 2016, 4, 6465-6471.

8 J. Chen, M. Yang, Q. Zhang, E. C. Cho, C. M. Cobley, C. Kim, C. Glaus, L. V. Wang, M. J. Welch and Y. Xia, Adv. Funct. Mater., 2010, 20, 3684-3694.

9 L. Zhang, L. T. Roling, X. Wang, M. Vara, M. Chi, J. Liu, S.-I. Choi, J. Park, J. A. Herron, Z. Xie, M. Mavrikakis and Y. Xia, Science, 2015, 349, 412-416.

10 D. S. He, D. He, J. Wang, Y. Lin, P. Yin, X. Hong, Y. Wu and Y. Li, J. Am. Chem. Soc., 2016, 138, 1494-1497.

11 C. Chen, Y. Kang, Z. Huo, Z. Zhu, W. Huang, H. L. Xin, J. D. Snyder, D. Li, J. A. Herron, M. Mavrikakis, M. Chi, K. L. More, Y. Li, N. M. Markovic, G. A. Somorjai, P. Yang and V. R. Stamenkovic, Science, 2014, 343, 1339-1343.

12 X. Lu, L. Au, J. McLellan, Z.-Y. Li, M. Marquez and Y. Xia, Nano Lett., 2007, 7, 1764-1769.

13 S. Chen, H. Su, Y. Wang, W. Wu and J. Zeng, Angew. Chem., Int. Ed., 2015, 54, 108-113.

14 A. P. Yadav, T. Okayasu, Y. Sugawara, A. Nishikata and T. Tsuru, J. Electrochem. Soc., 2012, 159, C190-C194.

15 S. Chen, H. A. Gasteiger, K. Hayakawa, T. Tada and Y. ShaoHorn, J. Electrochem. Soc., 2010, 157, A82-A97.

16 Y. Sugawara, T. Okayasu, A. P. Yadav, A. Nishikata and T. Tsuru, J. Electrochem. Soc., 2012, 159, F779-F786.

17 L. Zhang, W. Niu and G. Xu, Nano Today, 2012, 7, 586-605. 18 W. Luo, C. Zhu, S. Su, D. Li, Y. He, Q. Huang and C. Fan, ACS Nano, 2010, 4, 7451-7458.

19 M. S. El-Deab, T. Sotomura and T. Ohsaka, J. Electrochem. Soc., 2005, 152, C730-C737.

20 S.-P. Tung, T.-K. Huang, C.-Y. Lee and H.-T. Chiu, RSC Adv., 2012, 2, 1068-1073.

21 T.-M. Cheng, T.-K. Huang, H.-K. Lin, S.-P. Tung, Y.-L. Chen, C.-Y. Lee and H.-T. Chiu, ACS Appl. Mater. Interfaces, 2010, 2, 2773-2780.

22 X. Li, K. Yao, W. Lu and J. Wang, CrystEngComm, 2013, 15, 1289-1292.
23 T. X. H. Le, R. Esmilaire, M. Drobek, M. Bechelany, C. Vallicari, d.-l. nguyen, A. Julbe, S. Tingry and M. Cretin, J. Mater. Chem. A, 2016, DOI: 10.1039/c6ta05443a.

24 A. Both-Engel, M. Bechelany, O. Fontaine, A. Cherifi, D. Cornu and S. Tingry, ChemElectroChem, 2016, 3, 629-637.

25 C. D. Saquing, J. L. Manasco and S. A. Khan, Small, 2009, 5, 944-951.

26 D. Selloum, A. A. Chaaya, M. Bechelany, V. Rouessac, P. Miele and S. Tingry, J. Mater. Chem. A, 2014, 2, 2794-2800.

27 L. M. Alencar, G. L. Caneppele and C. A. Martins, Electroanalysis, 2016, DOI: 10.1002/elan.201600472.

28 A. Ruditskiy and Y. Xia, J. Am. Chem. Soc., 2016, 138, 31613167.

29 M. Jin, H. Liu, H. Zhang, Z. Xie, J. Liu and Y. Xia, Nano Res., 2011, 4, 83-91.

30 M. Grzelczak, A. Sánchez-Iglesias, B. Rodríguez-González, R. Alvarez-Puebla, J. Pérez-Juste and L. M. Liz-Marzán, Adv. Funct. Mater., 2008, 18, 3780-3786.

31 O. M. Magnussen, Chem. Rev., 2002, 102, 679-726.

32 M. Grzelczak, J. Perez-Juste, P. Mulvaney and L. M. LizMarzan, Chem. Soc. Rev., 2008, 37, 1783-1791.

33 A. Usher, D. C. McPhail and J. Brugger, Geochim. Cosmochim. Acta, 2009, 73, 3359-3380.

34 N. Zettsu, J. M. McLellan, B. Wiley, Y. Yin, Z.-Y. Li and Y. Xia, Angew. Chem., Int. Ed., 2006, 45, 1288-1292.

35 Y. Xiong, H. Cai, B. J. Wiley, J. Wang, M. J. Kim and Y. Xia, J. Am. Chem. Soc., 2007, 129, 3665-3675.

36 Y. Holade, K. Servat, T. W. Napporn and K. B. Kokoh, Electrochim. Acta, 2015, 162, 205-214.

37 Y. Xiong, J. M. McLellan, J. Chen, Y. Yin, Z.-Y. Li and Y. Xia, J. Am. Chem. Soc., 2005, 127, 17118-17127.

38 S. Hebié, L. Cornu, T. W. Napporn, J. Rousseau and B. K. Kokoh, J. Phys. Chem. C, 2013, 117, 9872-9880.

39 J. Wang, J. Gong, Y. Xiong, J. Yang, Y. Gao, Y. Liu, X. Lu and Z. Tang, Chem. Commun., 2011, 47, 6894-6896.

40 Y. Holade, K. Servat, T. W. Napporn, C. Morais, J.-M. Berjeaud and K. B. Kokoh, ChemSusChem, 2016, 9, 252-263.

41 D. Basu and S. Basu, Electrochim. Acta, 2010, 55, 5775-5779. 